\title{
STUDIES ON THE PATHOLOGICAL PHYSIOLOGY OF THE HEART
}

\author{
II. THE DYNAMICS OF AORTIC INSUFFICIENCY*
}

CARL J. WIGGERS, M.D.

NEW YORK

\section{PREVIOUS EXPERIMENTAL WORK}

Since Corrigan, ${ }^{1}$ in 1832 , first described and gave a logical explanation of the collapsing pulse often associated with aortic incompetency, clinicians and physiologists alike have given their interpretations of the circulatory changes inaugurated by a leakage of the aortic valves. In this, as in other provinces of medicine, it is important to differentiate between demonstrated facts and convenient assumptions to explain clinical observations. It is but natural, therefore, that the subject should have been the cause of considerable experimental investigation.

In 1878, Rosenbach" punctured the aortic valves in rabbits by a glass rod introduced through the right carotid. This caused no variation of mean arterial pressure. Cohnheim ${ }^{3}$ confirmed this result but Goddard ${ }^{4}$ obtained a fall of mean arterial pressure. De Jager, ${ }^{\overline{5}}$ in 1883 , obtained no variation after puncturing the valve segments in dogs, but in rabbits he observed a fall. This he explained as due to the fact that a relatively greater insufficiency is produced in rabbits.

Kornfeld, ${ }^{6}$ in 1896 , extended the experimental work by recording in addition the pressure in the left auricle. In a considerable percentage of his experiments the mean arterial pressure fell. He considered three possible causes of this fall: a backward leak, a deficient cardiac contraction, and a reflex dilatation of the blood vessels. The rise of right auricular pressure in some experiments favored, he believed, the first possibility. The back-flow during diastole, he reasoned, elevated the intraventricular pressure and so raised the left auricular pressure. Those cases in which the auricular pressure was not elevated he

\footnotetext{
* Submitted for publication Feb. 19, 1915.

* From the Department of Physiology, Cornell University Medical College.

* The second of a series of experimental and clinical investigations of pathological cardiac conditions made by means of optically recording instruments.

1. Corrigan: Edinburgh Med. and Surg. Jour., 1832, xxxvii, 225.

2. Rosenbach: Arch. f. exper. Path. u. Pharmakol., 1878, ix, 1.

3. Cohnheim: Vorlesungen über allgemeine Path., ii, 38.

4. Goddard: Acad. Proefschrift, Leyden, 1879.

5. De Jager: Arch. f. d. ges. Physiol., 1883, xxxi, 215.

6. Kornfeld: Ztschr. f. klin. Med., 1896, xxix, 91, 344.
} 
explained as due to a ventricular dilatation without increase in tension. Kornfeld also made the observation that the arterial pressure rapidly recovered from the fall and returned to its normal level, a fact conveniently attributed to a compensatory vasoconstriction.

It is evident that studies of the mean arterial pressure are not adequate to give any clear conception of the dynamics; in fact these experiments necessitate as many, if not more, theoretical assumptions than do the clinical signs and symptoms.

In 1908, Stewart, ${ }^{7}$ for the first time, endeavored to study the dynamic changes during separate cardiac cycles. This was accomplished by recording simultaneously the volume curves of the ventricles by a cardiometer and tambour and the arterial pressure changes by a Hürthle membrane manometer, the maximal and minimal readings being controlled by maximal and minimal valved manometers.

On rupturing an aortic cusp by means of a valvulotome devised by MacCallum, ${ }^{8}$ he found that diastolic pressure fell more than systolic, while, in some instances at least, the contour of the arterial pulse changed. The amplitude became greater and descending limb dropped more rapidly, corresponding to the typical collapsing pulse clinically observed.

The volume curve showed certain interesting but unexpected deviations-the rate of ventricular discharge estimated by the gradient of the downstroke was slower, the output per beat was increased only a trifle ( 5 c.c.) and the ventricular filling, occurring normally only in early diastole, continued throughout that phase. In spite of this extended period of filling, the ventricle was dilated less than is normally the case at the end of diastole, an observation that could be accounted for only by a greater tonicity.

Two facts are emphasized by this investigator, (1) that relatively little blood regurgitates during aortic insufficiency, and (2) that regurgitation can account neither for the large amplitude of the pulse nor for its collapsing character. The reason that little regurgitation occurs is logically explained as follows: The flow into the ventricle in diastole is determined by the size of the opening as well as by the pressure. At the end of systole, however, the pressure in the aorta is quite low (not more than $15 \mathrm{~mm}$. above that at the end of diastole). Since the aortic leak is small as compared with the mitral orifice, blood flows more readily through the latter under low auricular pressure than through the narrow aortic leak under higher arterial pressure.

The larger amplitude of the arterial pulse and its collapsing character cannot be due to a regurgitation, according to Stewart, for, (1) the

7. Stewart: The Archives Int. Med., 1908, i, 102.

8. MacCallum: Bull. Johns Hopkins Hosp., 1906, xvii, 260. 
great drop of pressure occurs before the dicrotic notch, and hence during ventricular systole, and (2) the collapsing pulse disappears if the peripheral resistance is increased. Stewart therefore interprets the collapsing pulse and great fall of diastolic pressure as due to a reflex dilatation of blood vessels, for (1) such changes are known to accompany vasodilatation and (2) irritation of the root of the aorta caused in his experiments a similar fall of diastolic pressure.

Experiments similar to those of Stewart were reported in 1909 by Zollinger, ${ }^{9}$ who used rabbits, cats and dogs as experimental animals. $\mathrm{He}$ also found that the output per beat was practically unchanged after insufficiency, but that the diastolic distention was always increased. The systolic arterial pressure was slightly elevated or unchanged. The diastolic pressure was invariably reduced and the pulse pressure thereby increased. No typical change in contour could be recognized in the curves taken with a Hürthle torsion manometer.

In 1911, MacCallum ${ }^{10}$ restudied the dynamics of aortic insufficiency by means of a perfusion system of stuch a nature that the heart intact within the thorax and inclosed within a cardiometer, ejected its fluid into a set of rubber tubes emptying into a reservoir from which, in turn, the right heart was fed. In this way the peripheral resistance was entirely eliminated.

The production of an aortic insufficiency by means of a valvulotome still caused a low diastolic pressure, while the systolic pressure remained unaltered. The amplitude of the volume curve indicating the systolic discharge increased and the ventricles dilated somewhat. Whereas, normally, the measured volume outflow from the rubber tubes and that calculated from the volume curve corresponded, after insufficiency, the output calculated from the volume curves increased while the measured flow remained unaltered. MacCallum concluded from this that the excess volume must have regurgitated back into the ventricle.

The greater systolic discharge, together with the lower tension of the arterial wall, account, according to this investigator, not only for the greater systolic filling and large pulse amplitude, but also for the low position of the dicrotic notch without the assumption of a peripheral dilatation.

\section{CRITICAL ANALYSIS AND SIgNificANCE OF PREVIGUS WORK}

It is necessary to consider critically to what extent it is demonstrated by previous experiments that the dynamic changes in aortic insufficiency are due either to aortic regurgitation or to peripheral vaso-

9. Zollinger: Arch. f. exper. Path. u. Pharmakol., 1909, 1xi, 193.

10. MacCallum: Bull. Johns Hopkins Hosp., 1911, xxii, 197. 
dilatation. It will no doubt be generally conceded that, if the production of a valvular lesion causes in an artificial circulation scheme in which peripheral changes are entirely eliminated changes similar to those in the body, it offers probable, though not absolute, evidence that the changes are not due to vascular dilatation. To be satisfactory as probable evidence, however, the records previous to the lesion should have a normal contour as well as a correct placement and reproduction of a dicrotic notch. After the lesion, the amplitude should be larger and the placement of the dicrotic notch should be lower. This is the case in the experiments reported by Marey on a mechanical model of the circulation, but not so in the records reported by MacCallum. If any conclusion could be drawn from a careful study of the so-called dicrotic a'aves before and after valvular lesions, as reported by the latter investigator, it would need to be that the dicrotic notch mounted higher on the descending limb during insufficiency (MacCallum, curves 2 and 5). As a matter of fact, however, owing to the use of inadequate apparatus, no oscillations resembling a dicrotic notch were recorded, but instead the inherent vibrations of the apparatus.

On the other hand, however, no satisfactory proof has been offered by Stewart that a dilatation occurs. The curves reproduced to show the possibility of producing a reflex vasodilatation on irritating the root of the aorta are clearly misinterpreted (Stewart, Figures 20 and 21). The fall of diastolic pressure was quite evidently due to a slowing of the heart ${ }^{11}$ and not to a reflex dilatation. The proof rests entirely on the necessity of explaining (a) the great fall of arterial pressure previous to the dicrotic notch, and (b) the supposed return of the pulse contour to normal after aortic compression or the administration of epinephrin. To anticipate, it may be stated that the former can be explained on an entirely different dynamic basis, while the latter observation proves to be incorrect.

The evidence seems to be conflicting as to whether an actual regurgitation occurs. MacCallum found the amplitude of the volume curve increased. Stewart and Zöllinger obtained no change. Stewart found that at the end of diastole the ventricle was dilated less than normally; Zöllinger and MacCallum noted considerable distention.

It is questionable to my mind whether this mode of experimentation is reliable or conclusive. During the time interval required to produce the lesion the circulation may have been changed, and by the manipulation itself it is difficult not to disarrange the cardiometer enough to account for the changes. A more fundamental objection, however,

11. For a detailed discussion of the effect of the length of previous heart cycles on systolic and diastolic pressures of subsequent beats, see Wiggers, Jour. Exper. Med., 1914, xix, 12; also The Circulation in Health and Disease, Philadelphia, 1915, p. 71. 
exists. The cardiometer is applied to two ventricles and records their volume changes simultaneously. Its use in the normal circulation is based on the presumption that the two ventricles functionate in a similar manner. Who shall dare to accurately analyze the composite curve obtained when one ventricle contracts as an after-loaded and the other as a loaded muscle? The results during insufficiency can at most show the changes in the volume output of the two ventricles. The fact that the amplitude fails to increase does not necessarily imply the failure of a regurgitation. It is conceivable, for instance, that a regurgitation may take place into the left ventricle, push the interventricular septum to the right and in so doing prevent the filling of the right ventricle by an amount equal to the increase regurgitation into the left. ${ }^{12}$

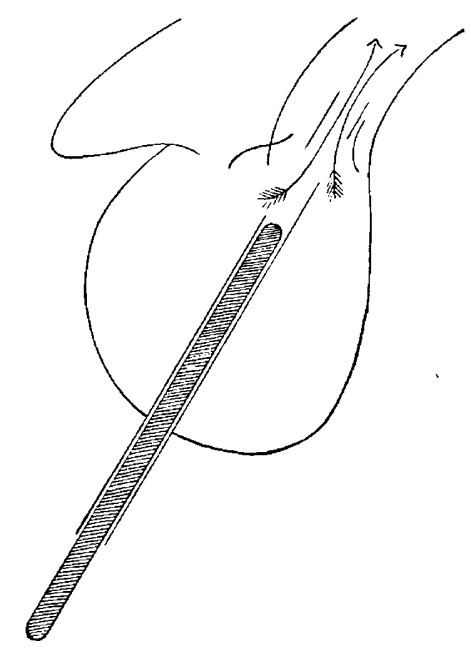

Fig. 1.-Diagram illustrating a simple method of producing aortic insufficiency in the expired heart.

A critical consideration, therefore, leads to the conclusion that clear and convincing proof has not yet been supplied by experimental work as to the dynamic changes brought about in insufficiency.

\section{APPARATUS AND PROCEDURES}

In this investigation the changes in the aortic and intraventricular pressures immediately after the production of valvular insufficiency were studied. The manometers, the recording apparatus and technic of their operation were essentially as described in a previous paper of this series. ${ }^{13}$ Mean pressure was read in addition from time to time by

12. Cf. results of Henderson and Prince, Heart, 1914, v, 217.

13. The Archives Int. Med., 1915, xv, 77. 
temporarily opening a side tube of the optical manometers connected with a damped mercury manometer.

The dogs were under chloretone anesthesia. The chest was opened after proper artificial respiration had been instituted. The pericardium was left intact as far as possible. Provisions for maintaining an effective auricular pressure, when desired, were at hand, as described in a previous paper.

Valvular insufficiency was produced in a temporary fashion on a principle similar to that previously reported in conjunction with $\mathrm{Du}$ Bois. ${ }^{14}$ The apparatus and method are diagrammatically illustrated in Figure 1. A metal sound $10 \mathrm{~cm}$. long and of $5 \mathrm{~mm}$. bore, closed by a snugly fitting glass plunger is forced through the pericardium and ventricular musculature at the apex and entered into the mouth of the aorta so that the slot $(2 \mathrm{~cm}$. long, $2 \mathrm{~mm}$. wide) on one end, palpated through the aorta, lies exactly at the level of the valves. When the plunger is withdrawn an insufficiency results. When it is pushed in, the valves close normally about the sound. The advantages of producing temporary valvular lesions in this manner over tearing or cutting the valves are: (1) the lesion can be produced while tracings are taken and the apparatus remains undisturbed; (2) the degree of insufficiency can be controlled and gaged by the size of the opening; (3) normal controls as to whether the circulation has changed for other causes can be obtained after the lesions have been studied; (4) the method is simpler and more certain, requiring no preliminary practice. It is used by the students in the laboratory course of clinical physiology under Dr. Du Bois, who produce one lesion after the other on the same animal.

The order of experimentation has, except for special reasons, been as follows:

1. Record of subclavian pressure curve by a calibrated optically recording manometer.

2. A second record after opening the chest.

3. A normal record of the subclavian pressure alone or in combination with left intraventricular pressure after the circulatory conditions which it is desired to study have been produced.

4. A record of same after inserting the sound into the aortic orifice.

5. Records during temporary insufficiency.

6. Records after normal valve action has been restored.

IV. THE EFFECT OF AORTIC INSUFFICIENCY ON THE CONTOLR OF THE ARTERIAL PRESSURE CURVE

Eighteen experiments have been performed. A few segments of records are analyzed as representative of the dynamic changes recorded.

14. Wiggers and Du Bois: Proc. Soc. Exper. Biol. and Med., 1913, x, 87. 

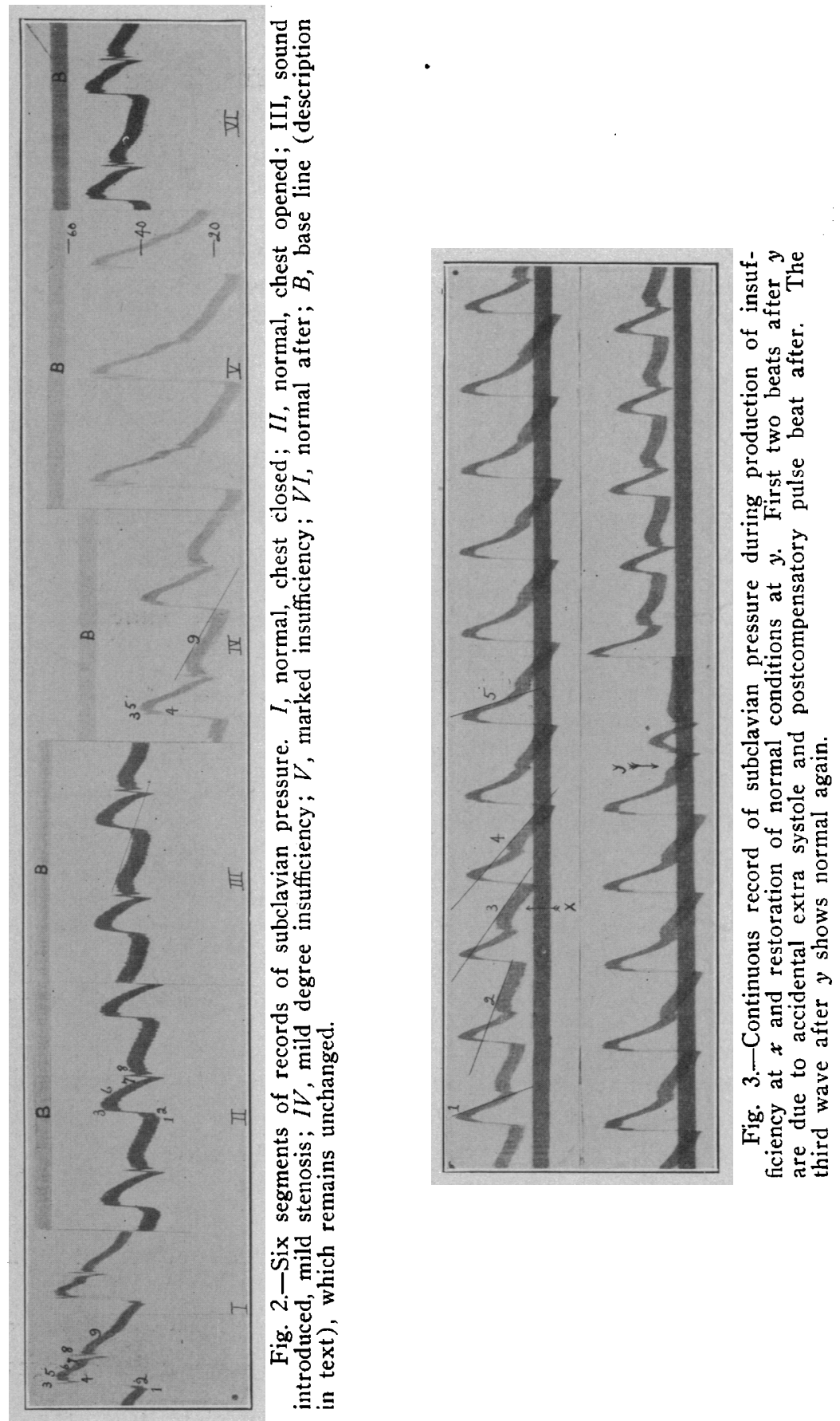
a. Arterial Curves Obtained in Cases with Impaired Systolic Output

Experiment C 59, Feb. 16, 1914 (Figure 2).

I. Subclavian pressure recorded by optical manometer $(\mathrm{N}=118)$; mean pressure $74 \mathrm{~mm}$. mercury. The curves show all the details described by Frank, namely, 1-2, preliminary oscillations during the isometric period of systole; $2,3,4$, preliminary oscillation of the arterial blood column; 5 , systolic summit; 6 , systolic decline; 7 , end of systole and beginning of incisura; 8 , vibration of closing valves (amplitude $=15 \mathrm{~mm}$.); 9, gradual decline during diastole.

II. Same, immediately after opening the thorax; estimated hemorrhage, 10 c.c. The systolic pressure has fallen more than the diastolic; the primary wave $(2,3,4)$ has almost disappeared; the systolic fall $(6)$ is more marked and the pressure at the end of systole is low. The incisura (7) is more gradual in its drop and the valve vibrations are slightly increased in amplitude $(16 \mathrm{~mm}$.) but the period is unchanged.

III. Same, after inserting sound. A slight stenosis has been produced in this case, as is shown (a) by the more gradual rise of the ascending limb (causing the broader band of light); (b) by the round top and entire absence of any trace of the primary oscillation.

IV. Mild aortic insufficiency combined with previous slight stenosis. Heart rate exactly the same. The changes observed are: The primary oscillation (1-2) is entirely absent; the primary oscillation (3-4) returns; the systolic summit is very slightly higher (compared to base line, $B$ ); the pressure at the end of systole (7) is slightly lower; the rate of diastolic drop (9) is more rapid and the pressure at the end of diastole is much lower.

V. Marked insufficiency. Same general changes as in IV but more pronounced. Systolic pressure is much higher and diastolic pressure much lower (compared to base line, B). The primary oscillations $(2-3,4)$ are larger.

VI. Normal curve taken immediately after sound was withdrawn from the valve opening. In comparing this curve with II, it is evident that the condition of the heart and circulation has improved rather than suffered as a result of manipulation. Both systolic and diastolic pressures are higher than in II, while the curve approximates more nearly that obtained from the unopened chest.

The experiment was repeated in still another way. While the record was being taken, as shown in Figure 3, an insufficiency was suddenly produced. This occurred early in diastole, as shown by the arrow. Immediately, the slope of the diastolic portion became steeper. In the first beat after insufficiency the systolic summit is slightly lower; in the second beat the primary oscillation is indicated, the upstroke becomes steeper (narrower line) and the systolic summit mounts to its normal level.

Comments: It is apparent that the mere act of opening the thorax at once alters the pressure relations in the aorta. The fact that the systolic pressure decreases more than the diastolic, as shown in the second segment of Figure 2, indicates that the change is due to a diminished output in consequence, probably, of the decreased effective pressure in the left auricle. It may be pointed out that the effects of valve lesions have probably been studied only under these abnormal conditions $b y$ those investigators who applied cardiometers to the heart. Such experiments, though carried on during a hypodynamic state are not without interest, however, as they are presumably typical of a certain class of clinical cases in which an insufficiency associated with a mild stenosis supervenes when the effective venous pressure is unusually low. Paradoxical as the statement may sound, it is evident that from a dynamic point of view an insufficiency is 

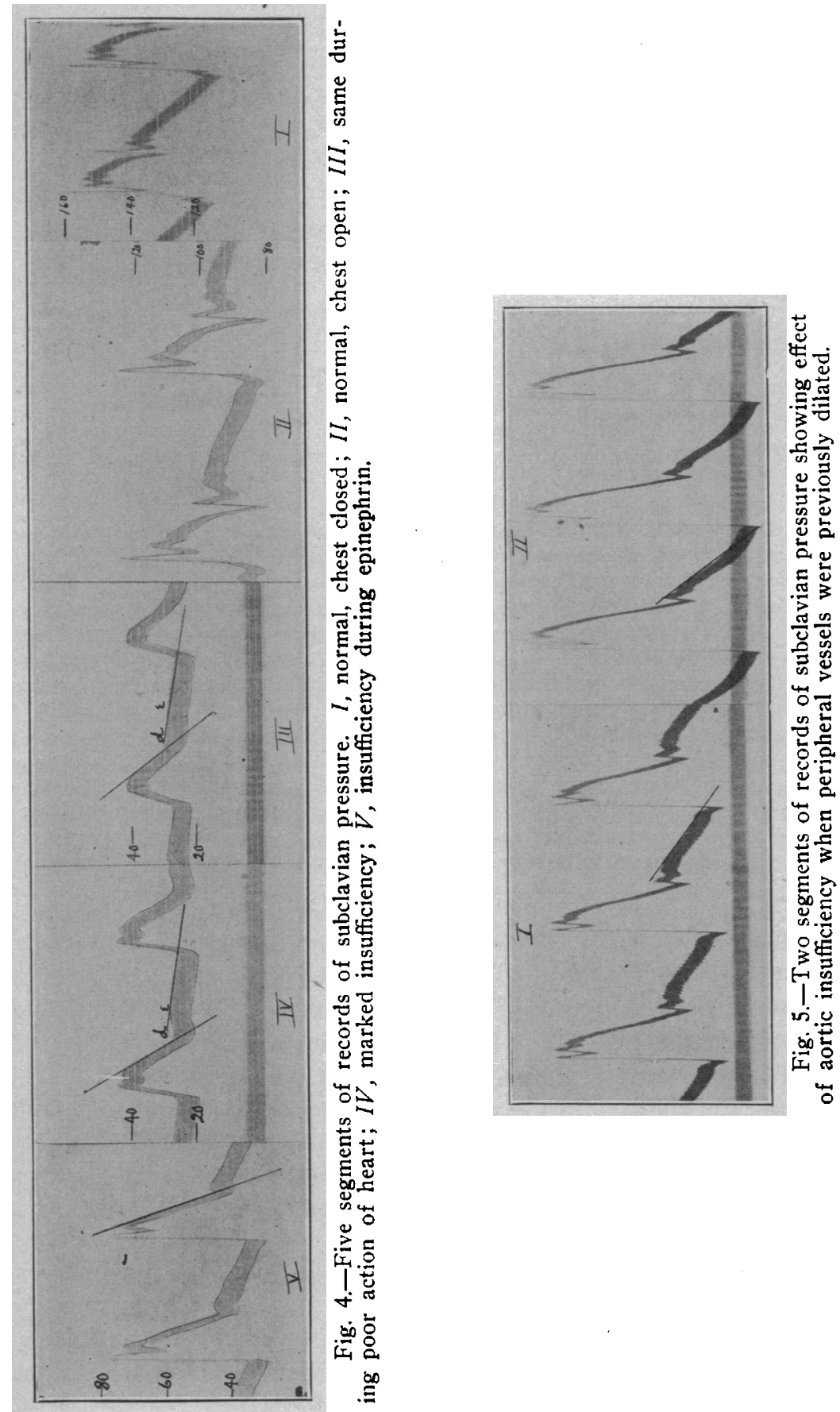
apparently beneficial in such instances. The curves of the central arteries, which were rounded and devoid of secondary oscillations, such as are indicative of an efficient circulation, regain many of their normal features, such as the primary oscillation, the larger amplitude and sharp incisura (IV and I in Fig. 2). As far as the slope of the descending limb is concerned, the pressure falls more rapidly during systole, making the pressure reached at the end of systole somewhat lower, but the greatest fall occurs during the diastolic portion, and this accounts for the very low pressure at the end of diastole.

\section{b. The Arterial Curves Obtained When the Muscular Power Is Impaired}

Experiment C 62, February, 1914. Figure 4 (curves mounted in order from right to left). Subclavian pressure curve with very sensitive manometer $(\mathrm{N}=50)$. The lower frequency probably accounts for the large primary oscillation and valve vibrations.

I. Chest closed, mean pressure $144 \mathrm{~mm}$. Curve shows all the normal details and additional vibrations of the sensitive undamped instrument.

II. Chest open - mean pressure $78 \mathrm{~mm}$.

III. After marked artificial respiration (acapnia ?) when the heart had become weaker and the output small - mean pressure $25 \mathrm{~mm}$. The arterial curves lose all their normal characteristics.

IV. Aortic insufficiency of marked degree. The amplitude of the pressure change becomes greater, the systolic pressure is higher and evidence of a primary oscillation reappears. The diastolic pressure is slightly lower, the gradient of the slope is more rapid both in systole and diastole. The normal curve taken after this resembles the curve shown in III.

V. Epinephrin during insufficiency. Both systolic and diastolic pressures rise, but the pressure curve is still of the collapsing type. Mean pressure $50 \mathrm{~mm}$. The primary oscillation becomes more prominent, giving the top a bifurcated appearance (pulsus bisferiens). During systole the pressure falls more steeply in spite of intense z'asoconstriction. This leads one to infer that the rate of systolic fall is not governed by peripheral constriction or relaxation, but by the height of pressure at the beginning of systole.

Comments: When, in addition to a low venous pressure, the inherent response of the ventricular muscle is poor, aortic insufficiency does not cause variations of great amplitude. Both systolic and diastolic pressures are low. Neither a distinct incisura nor valvular after-vibrations occur. The systolic summit shows a distinct notch. As far as the changes in the descending limb are concerned the fall during systole is more rapid, but the diastolic slope remains unaltered. This is the case whenever the pressure during entire diastole is very low. Epinephrin intensifies the collapsing nature of the pulse.

c. The Arterial Curves Obtained When the Venous Supply and Functional Power Are Normal but the Peripheral Resistance Is Low

Experiment C 60, Feb. 18, 1914. Figure 5. Dog under chloretone anesthesia, slow saline infusion.

I. The curve is taken with the chest open. Venous pressure equals $50 \mathrm{~mm}$. in the left auricle. Nitroglycerin previously administered. The curve shows all the details of a normal pulse except that the incisura is not so sharp, the amplitude is large and the pressure falls rapidiy during systole. 

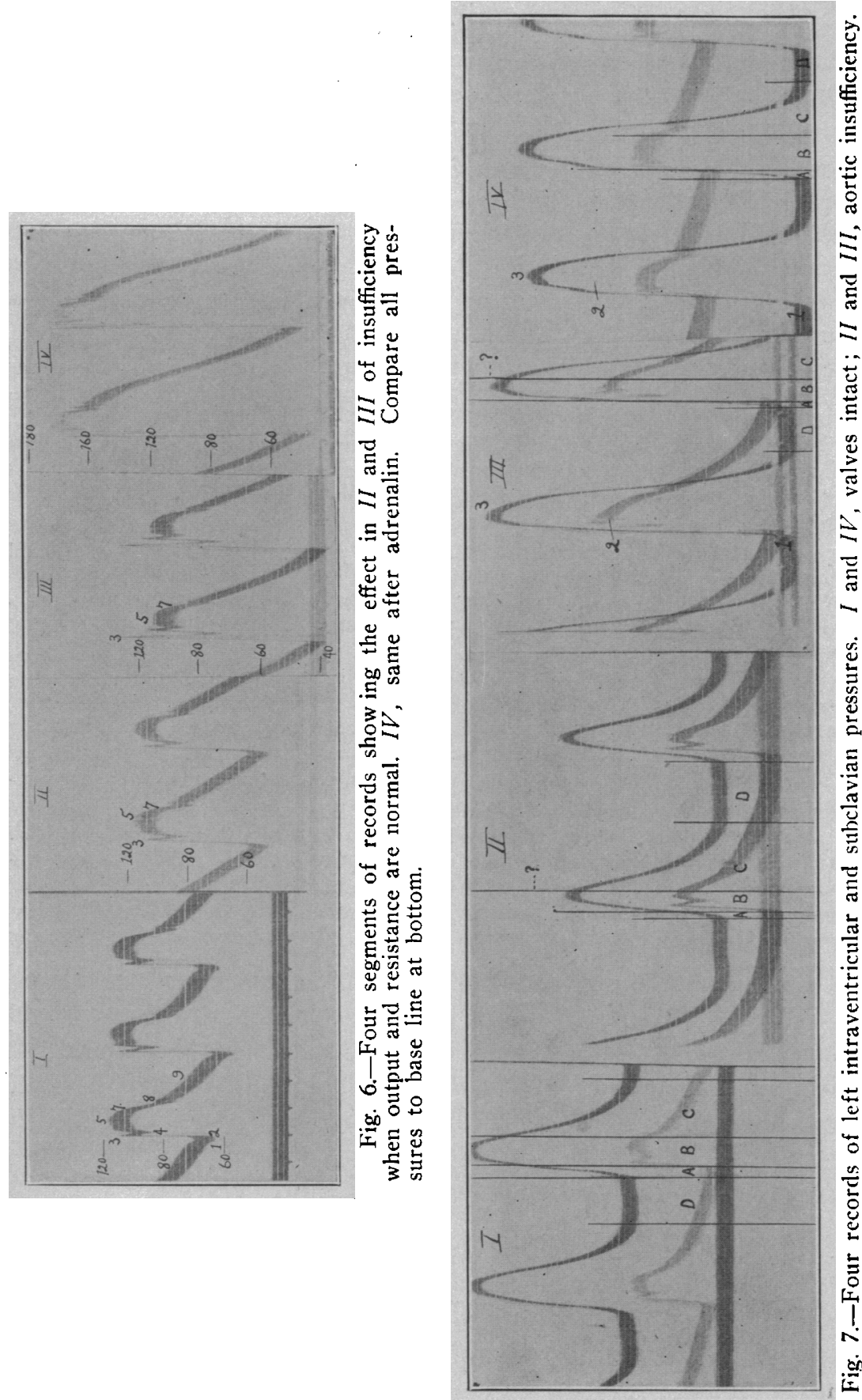
II. Curve during insufficiency. All the details of the low resistance pulse are retained with the exception of the preliminary oscillations $(1,2,3)$ occurring during the isometric period. The oscillations are all increased in amplitude, the systolic summit rises higher and the diastolic pressure reaches a lower level than the normal.

Comments: When the peripheral vessels are dilated and the output of the heart is normal, records of the largest amplitude are obtained, for, added to the tendency of a low resistance to increase the amplitude, is the effect of the lesion. The amplitude becomes greater because the systolic pressure is elevated and the diastolic pressure lowered. While the gradient of the pressure fall increases somewhat during systole, the most rapid drop responsible for the low pressure at the end of diastole occurs after the incisura.

\section{d. Cases with Normal Output and High Peripheral Resistance}

Experiment 6. Feb. 24, 1914. Figure 6. After opening the thorax the artificial respiration was reduced to a minimum, the dead space increased and a slow saline infusion continued. The thoracic aorta was slightly compressed by a special clamp.

I. Mean pressure, $106 \mathrm{~mm}$. mercury. Curve shows characteristics very similar to those of the curves from the unopened thorax. The broad systolic summit is accounted for by the higher resistance. The numbers correspond to those of Figure 2. The valvular vibrations are reduced owing to a higher pressure.

II, III. Two degrees of insufficiency. The preliminary oscillations 1, 2, disappear, the primary vibrations (3) are larger and the top is sustained during systole (5), as in normal curves. The rapid drop at the incisura occurs in a normal manner. The change occurs in diastole beginning at 7 . The fall is very rapid and complete so that the diastolic pressure is lower. The systolic summit also falls but not in proportion.

IV. After administration of epinephrin, 1 c.c. of a $1: 50,000$ solution. The entire curve has a larger amplitude. The ejection is more rapid but the contour of the systolic portion remains unaltered. The diastolic drop is more rapid, on the other hand, and of greater magnitude, indicating a greater regurgitation.

Comments: This type of experiment is comparable to clinical cases of insufficiency in which good heart action is associated with some peripheral sclerosis increasing the total arterial resistance. In such cases the change in contour is almost entirely limited to the diastolic portion. Increasing the activity of the heart, as by the injection of epinephrin, does not modify the contour of the systolic portion but increases the amplitude of the entire curve.

\section{e. The Effect of Aortic Insufficiency on the Contour of the Intraventricular Pressure Curves}

Experiment 62. Feb. 25, 1914. Figure 7. Simultaneous tracings of subclavian and left intraventricular pressures. The relative position of points is shown at the start of the second and third records.

I. Normal peripheral resistance, low venous pressure and a systolic output less than normal. Mean pressure, $40 \mathrm{~mm}$. The intraventricular pressure curve possesses the smooth character common to curves in which the initial intra- 
ventricular tension is low (see previous paper). The isometric rise (A) merges almost imperceptibly into the ejection period (B). C represents the active relaxation, and $D$ the interval of diastasis.

II. Aortic insufficiency with changes typical of the arterial pulse in this condition - mean pressure $24 \mathrm{~mm}$. The cycles are equal to those of I. An isometric period (A) persists but is shortened. The end of the ejection period is difficult to determine. Important, however, is the fact that the ejection period plus the relaxation period $(\mathrm{B}+\mathrm{C})$ remains unaltered, while the period of diastasis (D) is longer.

III. Aortic insufficiency after injection of saline and 2 c.c. of a $1: 100,000$ solution of epinephrin. The intraventricular record was shifted in relation to the base line in order to record the full amplitude. The most important change is that the intraventricular curve no longer remains smooth. A distinct bend in the ascending limb (2) separates the isometric and ejection periods. The systolic summit (3) rises exceedingly high.

IV. Normal curves during the action of epinephrin. The initial tension (1) is reduced but not in corresponding measure as the subclavian pressure is raised. The period of the isometric rise (A) is longer and terminates at a higher level (2). The summit (3) is lower, the period of active relaxation (C) is unchanged, but diastasis (D) is shortened in cases in which the same heart cycle is retained.

Comments: In regard to the intraventricular pressure curves, as compared with the arterial curves, aortic insufficiency causes, not an abolition, but merely a shortening of the isometric phase. The maximum pressure, as in normal hearts, is determined largely by the initial pressure which, during insufficiency, may be greater. This constitutes the immediate reserve mechanism of the heart which causes directly after the production of a lesion, a more vigorous output. In consequence of this continued greater activity, the ventricle probably hypertrophies. According to these conceptions, hypertrophy is a sequel, not a cause of an unusually large output of the heart in aortic insufficiency. The effect of insufficiency on the duration of diastasis, as revealed in these records, is precisely the opposite of the results of Stewart. Whereas this investigator observed a shortening or abolition of the period of diastasis, these curves show a distinct lengthening. Neither does it appear that the rate of active relaxation has altered. The evidence that the tonus changes was entirely lacking in all experiments.

\section{SUMMARY AND DISCUSSION}

The tracings obtained in this investigation, of which the illustrations are but selected segments, indicate that the details of the curves in aortic insufficiency depend, to a considerable degree, on the condition of the heart and the peripheral vessels at the time that the lesions are produced. Since all of these combinations and others are probably found in clinical cases, it may be well to summarize the chief changes in tabular form. 
Table of Changes in Aortic Insufficiency

\begin{tabular}{|c|c|c|c|c|}
\hline $\begin{array}{l}\text { Conditions of } \\
\text { Circulation }\end{array}$ & $\begin{array}{l}\text { Systolic } \\
\text { Summit }\end{array}$ & $\begin{array}{l}\text { Systolic Por- } \\
\text { tion of Fall } \\
\text { (to Onset of } \\
\text { Incisura) }\end{array}$ & $\begin{array}{l}\text { Diastolic Por- } \\
\text { tion of Fall } \\
\text { (After Valve } \\
\text { Vibration) }\end{array}$ & $\begin{array}{l}\text { Lowest Dias- } \\
\text { tolic Pres- } \\
\text { sure }\end{array}$ \\
\hline $\begin{array}{l}\text { Low venous } \\
\text { pressure, de- } \\
\text { creased sys- } \\
\text { tolic output. } \\
\text { Inherent ac- } \\
\text { tion of heart } \\
\text { good. }\end{array}$ & $\begin{array}{l}\text { Higher; more } \\
\text { peaked. }\end{array}$ & $\begin{array}{l}\text { Gra d i ent, } \\
\text { s o m e what } \\
\text { steeper. }\end{array}$ & $\begin{array}{l}\text { Gra d i e n t, } \\
\text { marke d ly } \\
\text { steeper. }\end{array}$ & $\underset{\text { depressed. }}{\mathrm{G} \text { e a t } 1 \text { y }}$ \\
\hline $\begin{array}{l}\text { I n h e r e n t } \\
\text { power of } \\
\text { heart poor. }\end{array}$ & $\begin{array}{l}\text { S } 1 \text { i g h t ly } \\
\text { higher; bi- } \\
\text { f urc at ed } \\
\text { peak. }\end{array}$ & $\begin{array}{l}\text { G r a d i e n t } \\
\text { steeper. }\end{array}$ & $\begin{array}{l}\text { Rate of fall } \\
\text { unaltered. }\end{array}$ & Unaltered. \\
\hline $\begin{array}{l}\text { Systolic out- } \\
\text { put normal; } \\
\text { per i pheral } \\
\text { vess els di- } \\
\text { lated. }\end{array}$ & $\begin{array}{l}\text { Higher; in- } \\
\text { creased a m- } \\
\text { plitude of } \\
\text { pri m a r y } \\
\text { notch. }\end{array}$ & Unaltered. & $\begin{array}{l}\text { Gra d i e n t, } \\
\text { steeper. }\end{array}$ & $\begin{array}{l}\mathrm{G} r \text { e a } t 1 \text { y } \\
\text { depressed. }\end{array}$ \\
\hline $\begin{array}{l}\text { Systolic out- } \\
\text { put normal. } \\
\text { P e r ipheral } \\
\text { res is tance } \\
\text { some w h t } \\
\text { increased. }\end{array}$ & $\begin{array}{l}\text { Slightly de- } \\
\text { creased. }\end{array}$ & Unaltered. & $\begin{array}{l}\text { Gra d i e } \mathrm{n} \mathrm{t} \text {, } \\
\text { much steeper. }\end{array}$ & $\begin{array}{l}\mathrm{G} \\
\text { depressed. }\end{array}$ \\
\hline
\end{tabular}

While the details of the curves vary under different conditions of the circulation, they show, in addition, certain constant changes, the significance of which can be definitely stated in dynamic terms. These changes it is desirable to discuss more at length.

1. During diastole, the pressure invariably falls more rapidly. ${ }^{15}$ Indeed, this is the chief fall accounting for the low diastolic pressure. The contrary records obtained by a Hürthle membrane manometer from animals and by clinical sphygmographs from man, must be attributed to faulty apparatus which exaggerates the systolic portion by fling and cannot record the events which distinguish diastole from systole.

Since the change in diastolic slope occurs within the interval of a single heart cycle and is independent of dilatation of vessels by nitroglycerin and constriction by epinephrin, it is evidently associated with the effect of the lesion itself. It is, however, quite unnecessary to assume that a large quantity of fluid regurgitates. It is essentially the pressure back-flow that it is important to recognize.

Quite contrary to expectation, the intraventricular pressure curve during diastole shows no deviation in its contour. The curve merely

15. The only exception occurs when the diastolic pressure is very low, owing to a very small output. 
fails to return to its normal level and in diastasis undergoes no further elevation, though arterial pressure continues to fall. The regurgitation of pressure occurs early after relaxation. The initial tension, that is, the tension to which the ventricle is submitted at the onset of the next ventricular contraction, is therefore never elevated so as to even approximate the intra-arterial diastolic. No detailed explanation can be offered without further investigation.

2. The preliminary oscillations normally present during the isometric period fail to occur. This is most readily explained by assuming that the ejection begins immediately after the onset of ventricular contraction. This would accord with the current view of the dynamics of this lesion. It is commonly recognized that the normal heart contracts as an after-loaded muscle, i. e., as a muscle which raises a weight so supported that it exerts its force only during the period of action. In other terms, the ventricle normally requires an isometric interval during which the pressure is raised sufficiently to open the semilunar valves and cause its ejection of blood. During aortic insufficiency, on the other hand, it is generally supposed that the ventricle is exposed to the full load of the aortic pressure during diastole and therefore contracts as a muscle from which a weight is permanently suspended. It has no isometric period, but the blood is ejected at once.

A careful comparison of the aortic and intraventricular records indicates that this view is not precisely correct. The curves shown in Figure 7 , for example, clearly indicate that an isometric interval exists but that it is shortened. This is accounted for by the observation already pointed out, namely, that although the initial intraventricular tension at the onset of systole is somewhat greater during insufficiency, it is always less than the diastolic pressure within the aorta. Hence a time interval is required to elevate the intraventricular pressure to the level of the aortic diastolic pressure. The relatively low diastolic pressure and the more rapid elevation of intraventricular pressure combine to make the isometric period short. The failure of preliminary oscillations may be due to the fact that the small rise of pressure which is necessary before ejection occurs is not sufficient to cause a bulging of the valve segments.

3. The pressure rises more rapidly and the primary peak is augmented or is reestablished when absent previous to the production of the lesion. In order to understand the more rapid rise of the curve and the aligmentation of the primary oscillation, it is necessary to bear in mind what may be termed the dynamic law of the ventricle. It has been shown by Frank in the case of the frog's ventricle, by me for the right ventricle of mammals and by Straub, Starling and Piper for 
the left ventricle, that the rapidity of the tension rise, the maximum height which the intraventricular pressure reaches, as well as the vigor of ejection, are determined, within limits, by the initial tension within the ventricle. It has already been pointed out that without producing any deviation in the pressure curve, the initial tension is greater in aortic insufficiency. The ejection period also begins at a lower level, owing to the lower diastolic pressure. Consequently, a larger quantity of blood is ejected into the aorta and with greater rapidity than is normally the case. It should be recalled that the primary oscillations are due (Frank) to the vibration that the entire blood column undergoes when suddenly ejected. If, for any reason, the vigor of ventricular ejection becomes small, the primary oscillation may entirely disappear.

The production of an aortic insufficiency by increasing the vigor of discharge at once acts to restore or augment the primary oscillation. The ejection may be so sharp that several vibrations occur, as in Figure 6, III and IV.

4. The more vigorous ejection of a larger quantity of blood in the earlier part of systole also raises the systolic summit to a higher level and accounts for the high systolic pressure. It is apparently not necessary to assume the existence of a cardiac hypertrophy or an arteriosclerosis in patients in order to explain this high pressure.

5. The high systolic summit once reached is not maintained, but drops away very rapidly during systole, so that, at the beginning of the incisura, the pressure is often lower than the normal. That this is not due to an increased peripheral flow brought about by vasodilatation is evident from the facts (1) that the change occurs too rapidly (within a single beat), (2) that it is present when the vessels are previously dilated by nitroglycerin and (3) that it is intensified rather than prevented by epinephrin. It is probably explainable by the fact that, while a larger quantity of blood is ejected with greater vigor early in systole, the total systolic discharge is not much increased. Consequently, during the latter portion of systole, less blood per unit time is actually ejected, and the peripheral flow exceeds the cardiac output per unit time. It is therefore more pronounced when the vessels are dilated and entirely absent when the aorta is clamped and the area of peripheral flow restricted.

\section{CONCLUSIONS}

From these considerations it may be concluded (1) that the characteristic changes of the pressure curve in the central vessels, as recorded by optical manometers, cannot be explained by any reflex vasometer mechanism set in operation by the production of an insufficiency, and (2) that the dynamic changes are accounted for by the 
fact that an aortic regurgitation increases the initial intraventricular tension, owing to a regurgitation of pressure during diastole; this, in turn, causes a more vigorous ejection of a larger blood volume in the early portion of the next systole. This may be accompanied by an actual decreased ejection during the latter portion of systole, thus, at once, accounting for the facts (a) that the systolic decline becomes steeper and (b) that the total systole output may not increase appreciably beyond normal.

First Avenue and Twenty-Eighth Street. 